\title{
Influence of Elasticity of a Control Device Mount on Vibration Control Performance for an Overhung Rotor System
}

\author{
Kazuki Mizutani ${ }^{\dagger}$ and Ryojun Ikeura \\ Department of Mechanical Engineering, Faculty of Engineering, Mie University, \\ 1515 Kamibama-cho, Tsu, Mie, 514-8507, Japan
}

(Received 23 September 2002; accepted 25 February 2004)

\begin{abstract}
This paper describes the influence of the elasticity of a control device mount on vibration control effects for an overhung rotor system. An overhung rotor is supported by a flexible bearing pedestal installed in four pairs of electromagnets, and the PD (proportional and derivative) control is performed in the system. These electromagnets give the control force to a flexible bearing and effectively reduce unbalanced vibrations of the overhung rotor indirectly. When the vibration control system is set up to industrial rotating machinery, a mount supporting the control system to the foundation may be assumed to be not rigid but elastic. The effect of stiffness and damping of the elastic mount on the vibration control performance is examined for the overhung rotor system by numerical simulations, and frequency response curves of the overhung rotor are calculated for several parameters. These simulations show that the vibration control performance of the overhung rotor becomes very low for a certain value of the elastic mount stiffness. Then, the effect of mount elasticity on the vibration control for overhung rotor is discussed in detail by the parametric study.
\end{abstract}

${ }^{\dagger}$ Member of the International Institute of Acoustics and Vibration (IIAV)

\section{INTRODUCTION}

With the improvement in performance of various machinery, vibration suppression of high-speed rotating machinery is greatly required. Vibrations of rotating machinery are mainly caused by unbalanced rotors. Since it is difficult to add damping forces to the rotating body itself, some rotorshaft systems are often supported by flexible bearing pedestals with a damping mechanism and/or a control device. ${ }^{1-18}$ For practical applications, passive-damping devices such as squeeze film dampers, ${ }^{1,2}$ gas dampers ${ }^{3}$ and dynamic vibration absorbers ${ }^{4,19}$ are used to reduce unbalance responses of rotating machinery. In order to decrease more effectively the rotor-unbalance response through the full operating range, many active vibration control apparatuses that use electromagnetic actuators have been applied in recent years. ${ }^{4-18}$

There are many types of rotating machinery with an overhung rotor, which is very sensitive to rotor unbalance. It is difficult to control the vibrations of the overhung rotor directly, because the vibration control system may be hardly equipped on the overhung rotor, due to restrictions in the construction of the rotating machinery. ${ }^{7,10,14-18}$

This paper describes the influence of the elasticity of the mount supporting the control device on vibration control effects for an overhung rotor system. The overhung rotor is supported by a flexible bearing pedestal installed in four pairs of U-shaped electromagnets in this system. The displacement signal measured at a flexible bearing pedestal is fed back to electromagnets. The PD control is performed in the system. The electromagnets give a control force to the flexible bearing and effectively reduce unbalanced vibrations of the overhung rotor indirectly. When the vibration control system is attached to industrial rotating machinery, a mount supporting the control system to the foundation may be assumed to be not a rigid body but an elastic one. The effect of stiffness and damping of the elastic mount on the vibration control performance is examined for the overhung rotor system by numerical simulations, and frequency response curves of the overhung rotor are calculated for several parameters. These simulations show that the vibration control performance of the overhung rotor becomes very low for a certain value of the elastic mount stiffness. Then, the effect of mount elasticity on the vibration control for the overhung rotor system is examined in detail by the parametric study.

\section{ANALYTICAL MODEL AND THE EQUATIONS OF MOTION}

The authors have proposed a hybrid-type vibration control device of an electric motor with an overhung rotor used in the textile industry. ${ }^{15,18}$ Figure 1 shows a schematic of a full-scale model of the motor used in a product line of the textile industry. A hybrid vibration control device composed of rubber springs (5) as passive device and four pairs of electromagnets (4) as active device is installed in the bearing pedestal on the anti-rotor side. This hybrid control device is a kind of controllably flexible bearing pedestal. The motor system with the vibration control device is mounted to a base by elastic plate springs (10) as shown in Fig. 1. Two eddycurrent-type position sensors (1) are installed in the electromagnets to measure the displacements of the controllable bearing in the horizontal and vertical directions, respectively. In this paper, the PD control is performed in the controller of the electromagnets to control the vibration of overhung rotor (2) indirectly. 